\title{
Plastic City/Elastic City. A critical interpretation of urban transformations
}

\author{
Antonio Camporeale ${ }^{12}$ \\ ${ }^{1}$ Dipartimento di Architettura e Progetto, 'Sapienza' Università degli Studi di Roma, Roma, Italy \\ ${ }^{2}$ Departamento de Proyectos Arquitectonicos. Universitat Politècnica de Valencia, Spain \\ E-mail: antonio.camporeale.7@gmail.com
}

\begin{abstract}
Globalization phenomenon caused effects that profoundly reduced the variety of reality, involving cultural, social and economic diversities, once recognizable and also identifiable through the study of architecture as a collective product of a civil community. In this context, architecture, as built and anthropic reality, suffered the shots of a revolution that has produced osmosis, hybridization, contamination, both diatopic that diachronic, now became synchronic and syntopic phenomena. Actually, you can find/ read common characters in the substrate, first typological then material, which, if critically interpreted, could indicate a possible and alternative way out of this apparent chaotic condition. In my opinion, following the consolidated basis of a theoretical and cultural heritage that has provided tools for critical reading of urban transformations, it is possible to distinguish two types of processes, usually traceable in cities. In order to rich this goal, I used the tools of the mechanical building discipline that identify: 'elastic'and 'plastic'transformations. The 'elastic'transformation produces 'elastic cities' because, at the end of the sustained stresses, the final configuration not change, instead the 'plastic' one produces 'plastic cities' when, at the end of the sustained stresses, the final configuration is not coincided with the initial one. These considerations / critical notes are the beginning of a research that, in my opinion, could offer inedited developments, both in the recognition of an unusual history of architecture, closer to his material essence, either as design and project tools, coherent with new consolidated environments.
\end{abstract}

Keywords: Globalization, cultural area, plastic/elastic transformations, urban fabrics.

\section{Introduction}

Talking about globalization without being able to contain the problem within certain limits is almost impossible. Synthetically, it is an overcoming process of ideals limits and boundaries and a homologation process of influences and consequences that affects various aspects of society at the cultural, economic, political, and technological level. It began to talk about globalization in the 90 s of the twentieth century, when market liberalization overthrew the active weight of state systems for private-financial systems in the global society: this process began after the
Second War Worldwide and asymptotically increased with the development of global communications technologies.

Before globalization, as we know it, would endanger this phenomenon, it was possible to import, transport, relocate forms and architectures from other distant countries. Recent news on finding Roman coins, discovered in archaeological excavations in far China, brought there by Chinese merchants, suggests the idea of a relatively globalized world already in ancient times even though there are no evidence that directly involved in architecture.

Then travels, especially linked to war 
experiences, were the first tools to transport and relocate distant, interpreted and rewritten forms and architectures. The experience of Emperor Hadrian, who in his great Villa made the reproduction, interpreted, partial and resized, of all the architectures he had to visit during his travels. And even before, when the ancient Greeks had reached the coasts of Sicily, Apulia and Calabria, they had brought with them the same forms that they built the temples of the Motherland, in larger proportions.

Of course, the influence that such import actions had on the known world is relatively small compared to today's globalized world where architectural forms and big cities have almost completely missed the connotations that distinguish them from each other. The world was not yet globalized as we mean it today, but in these attempts of 'transplantation' one could find the same phenomenon: Adriano wanted in his Villa images of his travels took in Roman provinces, condensed and built in architectures reproducing their shapes; The Greeks built temples in the Magna Grecia territories greater and mightier to affirm their relationship with the symbol of their faith in an extraneous and unknown context.

After the discovery of the Americas and, in general, with numerous explorative geographic journeys the colonization process began to contribute to the exportation of architecture, styles and ways of founding new cities.

More recently, the eclectic spirit, which contributed to consolidating the concept of copy and transplantation, shared the phenomenon globally: we could refer, for example, at the integral reproduction of the Parthenon in the city of Nashville in 1897.

During the early twentieth century, the International Style was promoting and enforcing an attempt to enforce rules for the diffusion of the new architecture, called 'modern': this attempt works, enforces and circulates globally thanks to rapid technological developments related to mass media, communication tools, faster dissemination press and a new important tool, that is photography: it always contributes more and more to the diffusion of architectural images. This is a fundamental topic for understanding the current globalizing phenomenon: it is the domain of the 'icon', of the 'logo', symbol in architecture that is now a commercial vehicle and an economic mechanism.

Global trade malls, theme parks, and finally, those unique buildings designed by so-called 'archistars', become commercialeconomic operations, which, on one hand, produce a positive result, for example, in the transformation of degraded urban areas; on the other, trigger a slow and inexorable diabolical process of detachment from the deep meaning that stays inside architecture: the close bond with human being who produces and uses it. This bond has remote origins and concerns the way to transform the reality in which man lives. Reality that is made of matter, of which the ability to transform into building material must be recognized. The construction material will be increasingly elaborated and become a completed element and component that, by aggregating it, will form the architectural organism. This process of transformation of matter has allowed the codification of two worlds with common general characteristics 'readable' in architectures (and urban fabrics as we try to demonstrate in this fragmentary notes): a 'masonry-plastic' world whose characters are linked to the transformation of the stone material; a 'wooden-elastic' world, whose characters are related to the transformation of woody material.

It is relatively easy to recognize and distinguish, even in this current complex global context in which we live in, masonry architectures and wooden architectures and the cultural area in which they have been developed and built too. This has been proven by numerous scientific studies and constitutes a process that links the formation and transformation of architecture and city to the specific site, and thus to the matter, in which they were built. The stratification and consolidation of constructive habits have been inherited and transcribed in architecture. The city, which is material and social aggregation, on a larger scale, resembles their common features of architecture.

In the field of architecture, globalization phenomenon caused effects that profoundly reduced the variety of reality, involving cultural, social and economic diversities, once 
recognizable and also identifiable through the study of architecture as a collective product of a civil community.

Architecture, as built and anthropic reality, suffered the shots of a revolution that has produced osmosis, hybridisation, contamination, both diatopic that diachronic, now became synchronic and syntopic phenomena.

Actually, you can find/read common characters in the substrate, first typological and then material which, if critically interpreted, could indicate a possible and alternative way out of this apparent and chaotic condition.

In my opinion, following the consolidated base of a theoretical and cultural heritage that has provided tools for a critical reading of urban transformations, it is possible to distinguish two types of processes, usually traceable in cities.

In order to rich this goal, I used the tools of the mechanical building discipline that identify: 'elastic' and 'plastic' transformations. The 'elastic' transformation produces 'elastic cities' because, at the end of the sustained stresses, the final configuration not change, instead the 'plastic' one produces 'plastic cities' when, at the end of the sustained stresses, the final configuration is not coincided with the initial one.

These considerations/critical notes are the beginning of a research that, in my opinion, could offer inedited developments, both in the recognition of an unusual history of architecture, closer to his material essence, either as design and project tools, coherent with new consolidated environments.

\section{Plastic City}

The latest systematization of the typomorphological discipline plastically reorganizes the existing theoretical heritage and prepares itself to the possibility of a coherent and continuous update, favored by many open questions as small crevices of a ductile and resistant structure, as components that are reinforced/completed with new, complementary and coherent theoretical structures, obtaining other new units in preparation. Considerations which have been stratified until now ideally found an adherent graft just in these crevices and claim fit into the ongoing process of theoretical elaboration that, for each 'fusion', proposes a new coherent, albeit partial, result. It would, that is, examine in depth the sense of the future/possible 'Plastic City', advocated at the conclusion of reflections on the evolving masonry-plastic world.

The characters of the 'masonry-plastic' world derive from the transformation of the matter available in large quantities in areas such as the Mediterranean basin. Man recognizes in stone those properties that make it usable and exploitable in the construction: he encounters pieces of such dimensions and organizes them in a way they could stack themselves on, one on another, and form, for example, typical dry stones walls defining private property land. As the piece of stone is excavated and worked, it joins in increasingly complex constructions in which each piece assumes a particular role and a particular form, making it unique and identifiable in the architectural organism. Constructions that derive from this 'plastic' process take on a massive, organic, heavy character.

'Plastic' city consists of a smaller scale elements that work together spatially and constructively to the organic unity of urban composition. Collaboration between parts is necessary because the system of elements shares the same goal: the life of the city itself. Those transformations, that urban organisms undergo in a continuous way, are finally called 'plastic' because, when stabilize the temporary balance achieved, they present new unitary configurations that include and merge the existing reality with the new proportioned one. Plastic city is, for those reasons, organic and resilient: routes, paths, buildings, fabrics not only blend them together, including and obtaining new forms, coherent and anthropically measured, but are ready to adjust their spatial structure in response to violent external attacks represented by exceptional events to which they oppose resistance, even constructive.

A 'plastic' city presents organic, spatial, constructive, and finally aesthetic characters 
related to linguistic expression of logical relationships between constructive elements, making it visible and then exteriorly readable. Architectural expression is the last degree, concise and intelligible, of a process, the typological process that accumulates costumes and actions that always repeat, encoding them in language and shares them spontaneously in the community of a social and cultural neighborhood.

A 'plastic' process, which physically involves matter in its arranging and organizing phenomenon, even more complex, through man critical actions: the measure of a brick has remained the same since its first definition as the only one to adhere to the hand size that would have had to take, lift and place, composing the wall.

Architectural language is coded from repeated constructive costumes that become common rules, unwritten but present in the spirit of human kind of each era: the construction of a wall included, when it reached a certain height, the 'beating' of the setting-up plan for the opening of windows; in Roman area it was common to setting-up a subfloor done with a different material, usually composed of two rows of regular bricks that established a material discontinuity in the vertical plan of the wall over the other resistant material, for instance the Roman tuff.

In Rome, for example, a long building tradition, one would say, that is interesting for its 'plastic' ability to turn itself into rules/language, to adhere to the materic/ constructive significance and express, ultimately, the aesthetic attitude of each individual builder: these rows, internal to the own construction and belonging, one could say, to the technical/construction discipline, turned into recognizable elements, such as the 'marcadavanzale' (possibly translated with 'windowsill stringcourse') that is a horizontal element realized with travertine bands that together express and plasticize the process of assimilation and codification of primitive constructive actions that were its 'spiritual' and unconscious legacy.

The contemporary 'plastic' city coincides with its central core that continues to change with 'plastic' transformation processes involving pre-existing tissues, obtaining a new configuration in continuity with the originating formative process; they are, for example, all those compact peripheries, made up of compact fabrics that resist to the sprawl phenomenon. In this case, the aggregation of several in-line residential units does not occur by physically sharing perimeter walls, as it was a few decades ago, but we could individuate some solidarity between buildings that continue to place side by side and form closed enclosures. On a larger scale, the compact city is still structured on the ancient territorial connection routes that, despite the strong pressure of an 'elastic' way of planning that destroyed the solidarity of built urban fabrics, continue to be important arteries, often converging in the urban pole of the oldest and most vital core of the city.

\section{Elastic City}

The 'elastic' city is formed in places where the matter, available in large quantities, is wood. In Europe we could trace those cultural areas where this process took place that are in the Center and Nordic countries where there is a massive amount of woods. In such areas man has had to recognize in the woody matter the aptitude to be transformed into building material: first, recognizing its intrinsic 'elasticity' potential, that is, the property for which wood can be, for example, bent and not broken up to a certain amount of load.

For this reason, the first huts had to resemble those represented and suggested by Violett-leDuc: trunks of trees, bent and knotted in the higher part. This represented the supporting structure of the hut, but not its closing space system. This was followed by the placement of a dense foliage supported by the underlying elastic structure. This way of defining space will persist for a long time and will come, critically interpreted and innovated, to this day. Due to needs of space inside the hut, which is objectively difficult to handle for the formation of unused corners, it is built a wall, that can regularize and orthogonalize the space, load-bearing the foliage cover: this process assumes a special exploitation of the wood material that comes most elaborated, 
standardizing and unifying, in a way, the shape of the single element. The element, no longer 'met' fortuitously but 'searched' and selected for its size and structural capabilities, is now compounded in an increasingly complex structure, where it is necessary to close the space at a later time.

Typical half-timbered houses -you could see, for example, the typical German 'Fachwerkhäuser'-, spread in high-availability woody areas, are a clear example of this approach: the wood structure remains visible and it is therefore possible to distinguish it from the filling material of the closures which is, in turn, left exposed or plastered and painted. This approach consolidates itself and becomes typical: first you build the structure and then you close the spaces inside it. A common feature that 'unites' these buildings is the seriality of those elements: beams and pillars, long-limbed elements with a predominant dimension to the other two, when aggregated, form structures where the knot is often determined by overlapping them and junctions, more or less complex.

This gives the typical 'serial' character related to the opportunity, ideal rather than directly practical, to eliminate one of these linear elements without causing distortions in the overall configuration of the building. In my opinion, we can find this character, on a larger scale, in 'elastic' cities: buildings approach each other without sharing load-bearing structures, as instead in the case of the masonry-plastic area where load-bearing walls are physically shared with two or more buildings. This is evidenced by the persistent presence of the pitched roof with the top line orthogonal to the path, obtaining the 'individuation' of the building in its autonomy, within the urban fabric of which it is a recognizable component. The formative process of the medieval urban tissues of the Center and Northern Europe, when not derived from a previous Roman layout, generally follows the same phases identified in other contexts of the same period: basic building construction is set on the main route that generally converge in a pole, in the most important point of the urban settlement that is almost always represented by the religious building of the church and the civil building; in a second phase, secondary routes appear with the basic building that is set on these; finally, appearing connecting routes and, in some cases, break-through routes.

But the 'serial' character of buildings, thanks to an impressive technological development, will lead to the definition of the modern city which, in my opinion, represents the peak of the process and condenses all the intentional characters of the 'elastic' city. The new modern city, in fact, losing the minimum cohesion of traditional compact urban tissues, eliminates any possibility of structural sharing of buildings, that become isolated elements placed at certain distances from each other.

Thus, we have peripheries in which sprawl leads to a proportional expansion of urban areas: the obsessive repetition of the same equal elements forms urban tissues where it is potentially possible to replace an element or more elements without involving others, causing only relative transformations involving the immediate neighbourhood. In conjunction with the process of serialization and discretization of urban tissues, another parallel process begins and predicts their vertical growth.

The skyscraper thus forms the sprawl space set on multiple levels. The skyscraper may have a residential or special/public function, but its global conformation condenses characters that, in my opinion, could be identified: it is a linear element, with a prevalent dimension in the space over the other two and is characterized by its relative isolation. The skyscraper does not combine with other skyscrapers, it not constitutes a traditional horizontal urban fabric, it is a vertical urban fabric (Ciotoli, 2017) in its own right.

From the point of view of architectural language, it maintains the 'serial' and 'elastic' characters of the elements that make up it: beams and pillars form framed structures that are often visible on the facade along with a transparent closure. They are regularly replaced without involving the context, or involving the context relatively. The elastic city is therefore a city that is transformed by maintaining its configuration relatively unchanged: as when an elastic structure regains its initial configuration after the stress has been exhausted. 


\section{Conclusion}

The way in which cities could be 'read' and the kind of transformations connected to them is, in my opinion, useful to interpret, through the 'technical/constructive' filter, these general mechanisms that have always governed their development. Mechanisms that could be connected at the provisional end of a continuous and still ongoing formative process, and whose general common features can be read despite the strong phenomenon of continuous and accelerated hybridization (Ieva, 2011) that has affected that process.

Not only technological hybridization, which presupposes a unitary mixing and progressive advancements, a cultural hybridization that blends in some way and potentially creates a new society, but an imposing and closed 'colonization' tends to erase some characters and set others.

It may be possible, in my opinion, to control this hybridization, that is the critical mixing phenomenon of different starting conditions for the purpose of obtaining a new enriched unit in which all parts are collaborating through the 'plastic' mechanism: measuring the degree of interference, collaboration, inclusiveness of those various parts, including physical, for the construction of basic and specialized urban tissues, allows us to obtain continuity in transformation and, in case starting conditions are of an 'elastic' type, obtain a new unit result, that is serial, discrete, closed, isolable.

The control of the 'colonizing' phenomenon could be interpreted through the 'elastic' filter, understood as a violent substituting act, in which the starting conditions are not fused into a new unit: in such contexts where, for example, densification represent the urgent need for urban transformation -trying to interrupt the process of territorial dispersioncould be triggered by a 'plastic' approach that tends to the aggregation, even structural, of isolated elements by applying critically and simultaneously the general formative laws extracted from the reading of inherited urban contexts.

In conclusion, this initial and partial study proposed in this article might indicate, in my opinion, a new line of research on the definition of a new critical approach, not only for the preservation of the existing built realities, but also for their necessary transformations: to understand the deep mechanism, more or less 'elastic' or more or less 'plastic', of urban tissues could, in my opinion, indicate the most coherent way to be able to intervene critically in these ongoing transformation processes. 


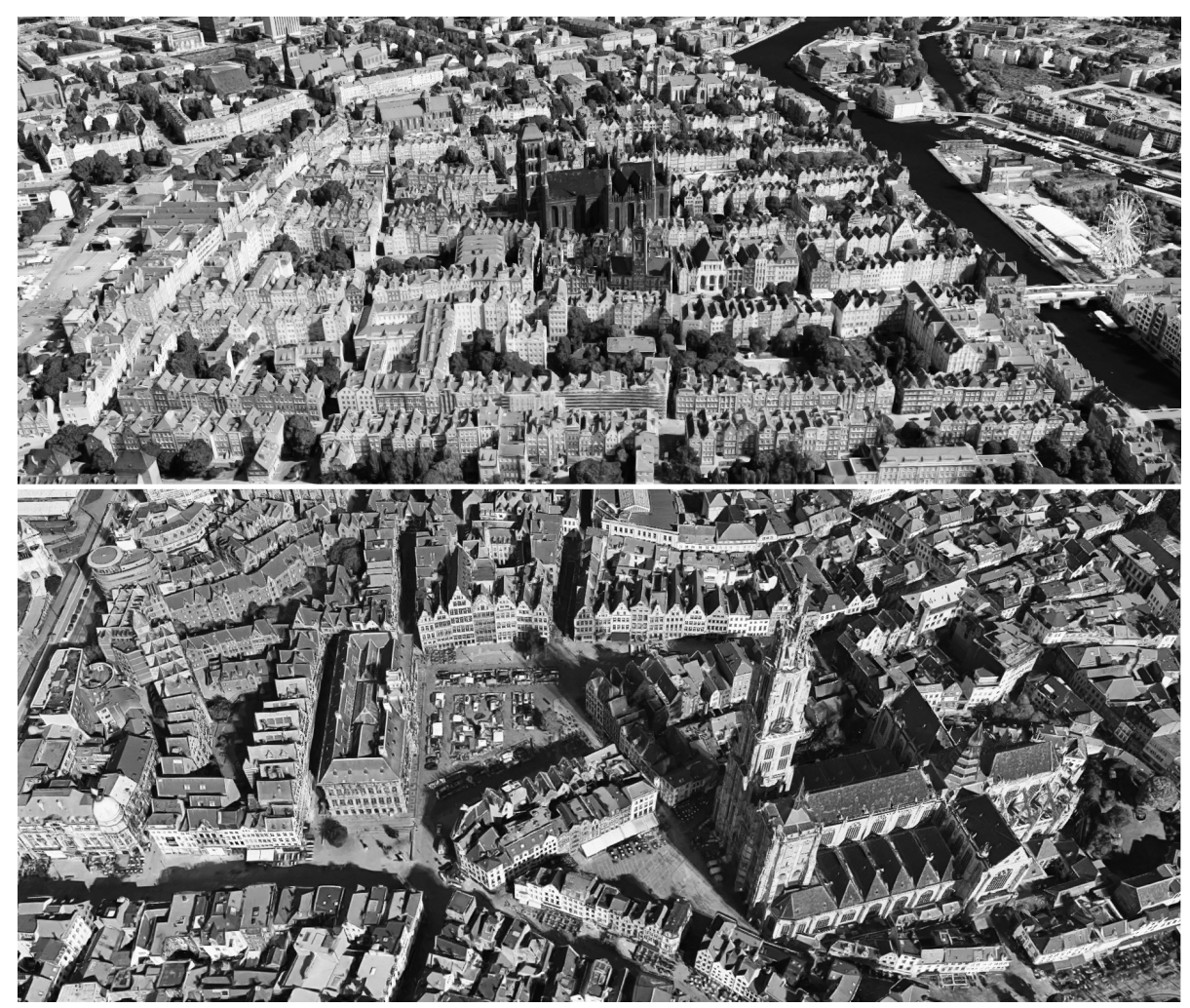

Figure 1. Historical Elastic Cities. Gdańsk, Poland (above), Antwerp, Belgium (below)

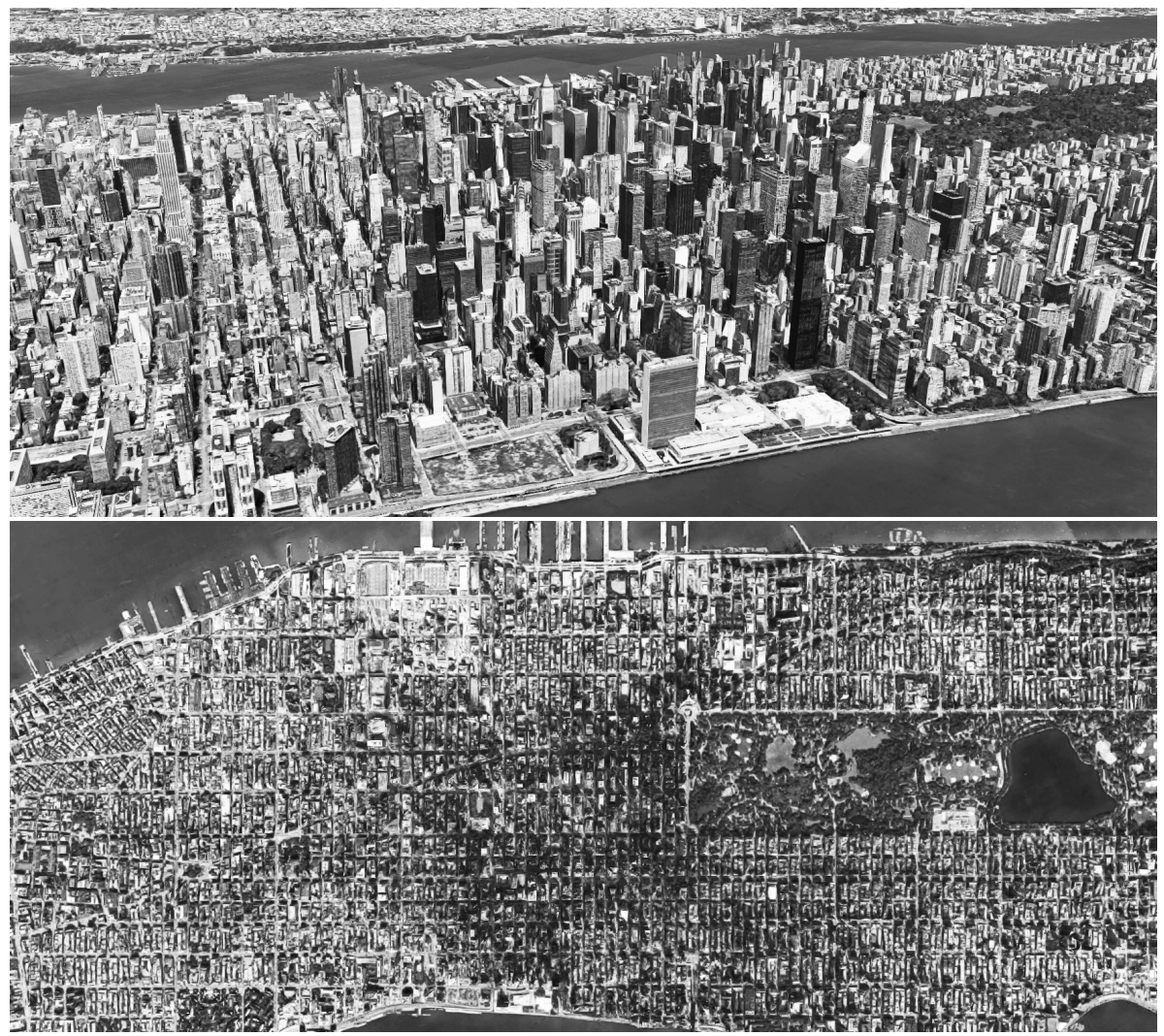

Figure 2. Contemporary Elastic City. New York, U.S.A. 

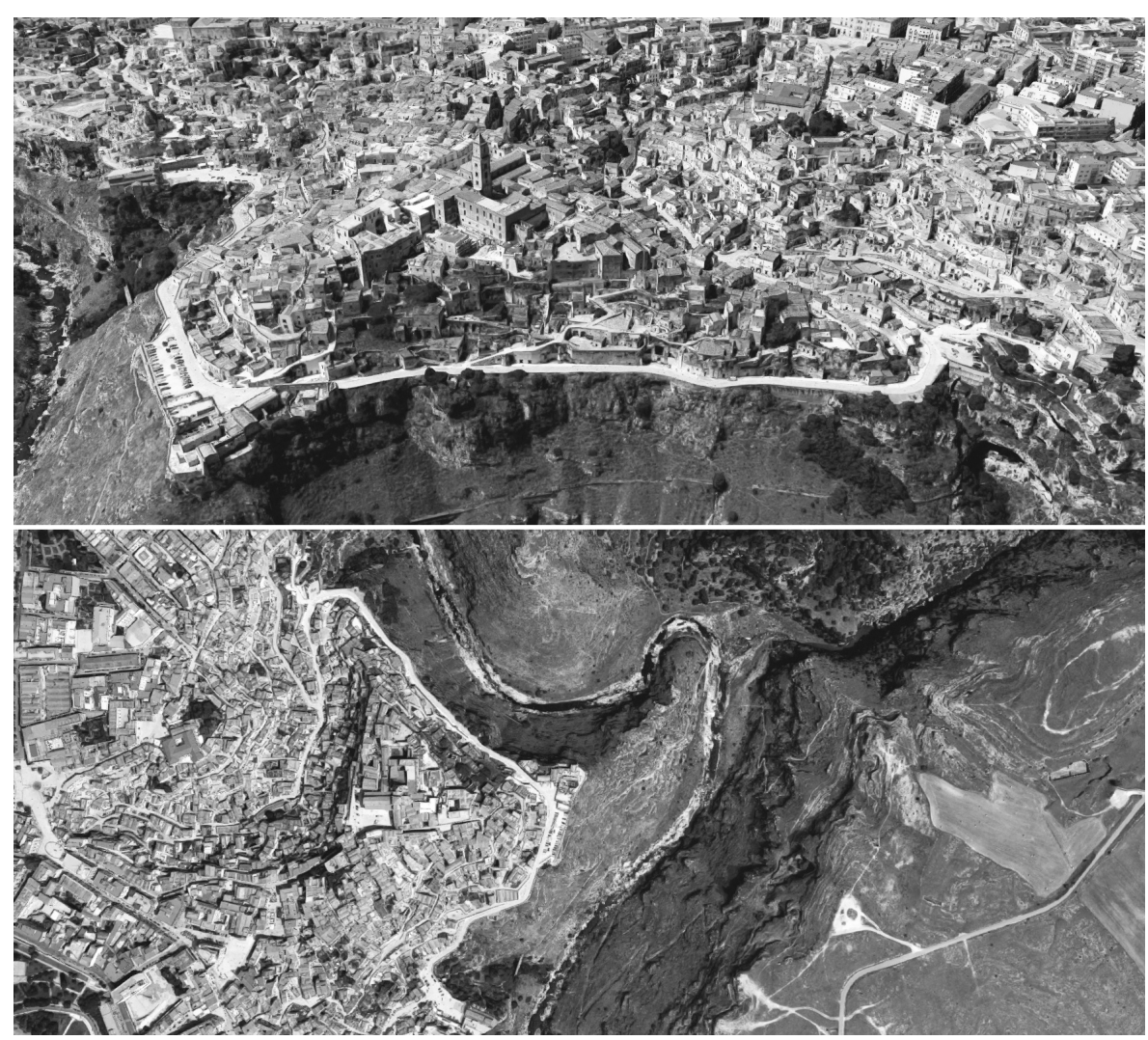

Figure 3. Historical Plastic City. Matera, Italy.

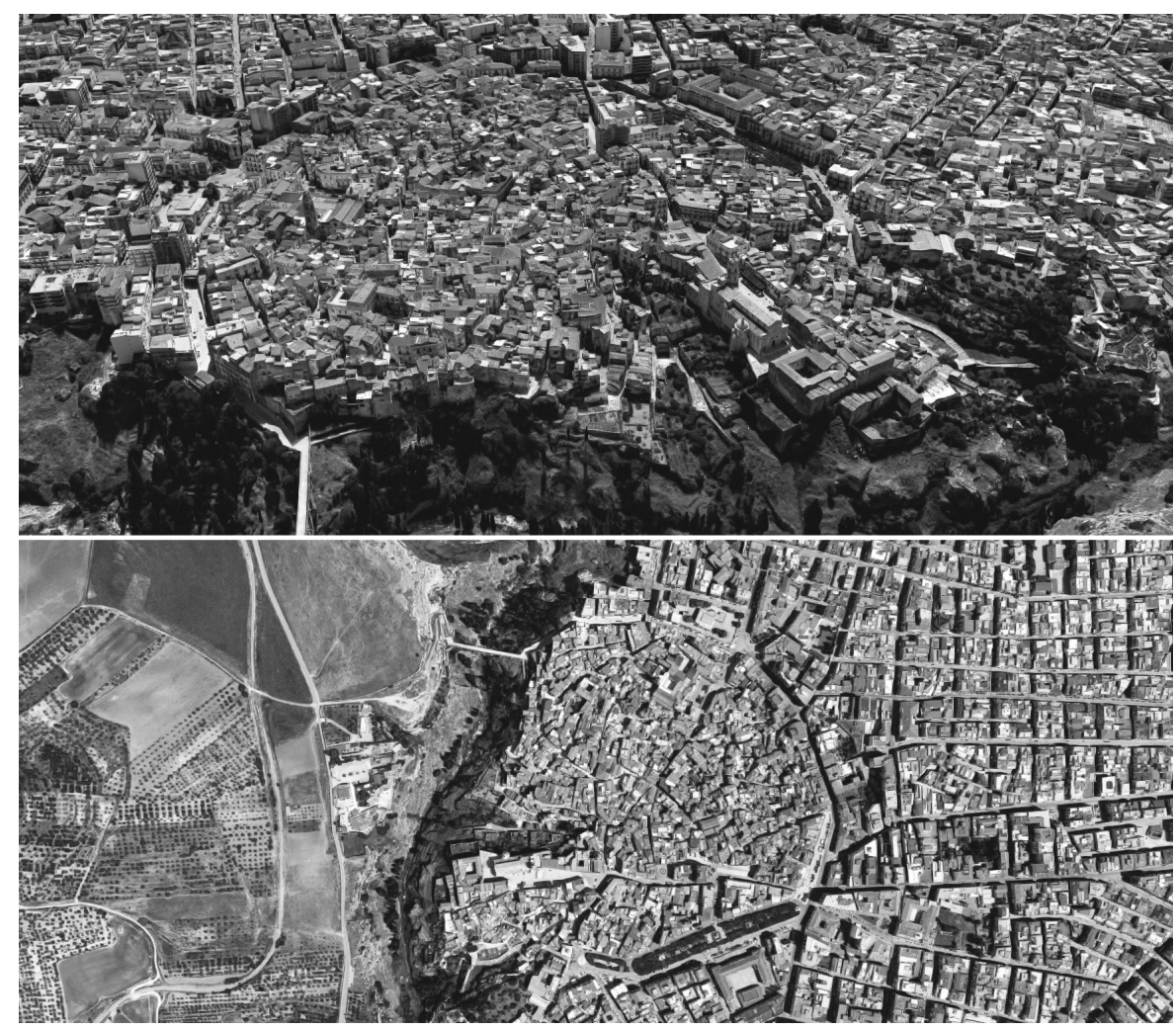

Figure 4. Historical Plastic City. Gravina in Puglia, Italy. 


\section{References}

Amato, A. R. D. (2017) Architetture di recinti e città contemporanea. Vitalità del processo formativo delle strutture a corte (Franco Angeli Editore, Milano).

Caniggia, G. and Maffei G. L., (1979) Composizione architettonica e tipologia edilizia I. Lettura dell'edilizia di base (Marsilio Editore, Venezia).

Caniggia, G. and Maffei G. L., (1984) Composizione architettonica e tipologia edilizia II. Il progetto nell'edilizia di base (Marsilio Editore, Venezia).

Carlotti P., Nencini D., Posocco P. (2014) Mediterranei. Traduzioni della modernità (Franco Angeli Editore, Milano).

Ceragioli, G., 'Ibridazione Tecnologia', (from the website of the Polytechnic of Turin: http://areeweb.polito.it/ricerca/crd-pvs/ documenti/531.pdf) accessed 6 May 2017.

Ciotoli, P. (2017) 'Tessuti Verticali. Interpretazione architettonica e urbana del grattacielo', unpublished $\mathrm{PhD}$ thesis, Supervisor Prof. Giuseppe Strappa, Università degli Studi di Roma 'Sapienza'.

Ieva, M. (2011) 'Caratteri dell'architettura nell'età della globalizzazione', in D'Amato, C., (2011) La Ricerca. I ${ }^{\circ}$ Congresso internazionale Il progetto di architettura fra didattica e ricerca, Conference Proceedings (Polibapress, Bari).

Strappa, G., Carlotti, P., Camiz, A. (2016) Morfologia urbana e tessuti storici. Il progetto contemporaneo dei centri minori del Lazio (Gangemi Editore, Roma).

Strappa, G. (2014) L'architettura come processo. Il mondo plastico murario in divenire (Franco Angeli Editore, Milano).

Strappa, G. (1995) Unità dell'organismo architettonico. Note sulla formazione e trasformazione dei caratteri degli edifici (Franco Angeli Editore, Milano). 